\title{
Socialização, profissionalização e trabalho de professores iniciantes
}

\section{Socialization, professionalization and the work of novice teachers}

\author{
Maria Isabel de Almeida* \\ Selma Garrido Pimenta* \\ José Cerchi Fusari*
}

\begin{abstract}
RESUMO
O presente artigo tem como ponto de partida a indagação acerca de como os modos de inserção profissional de professores iniciantes repercutem na vida desses profissionais. Para buscar respostas a essa indagação, investigou-se as formas como se processa a inserção de licenciados egressos de uma universidade pública como professores nos sistemas escolares públicos do estado de São Paulo. Foram entrevistados 20 professores iniciantes, de distintas áreas de conhecimento que estavam atuando em escolas públicas nos primeiros cinco anos após a formatura. Tomou-se como categorias de análise socialização profissional, profissionalização docente e trabalho docente. O texto busca compreender as formas de ingresso no magistério, o aprender da profissão, relação com os parceiros de trabalho, formas de aproximação com o ambiente profissional, inserção em escolas do sistema público, condições de exercício da docência, motivação para ingresso e permanência na profissão, dificuldades e expectativas quanto ao futuro profissional. Os dados qualitativos, obtidos nas entrevistas semiestruturadas, foram analisados na confluência com a literatura sobre o tema e à luz da concepção crítico-dialética, o que permitiu evidenciar a complexidade e as contradições dos processos de socialização e profissionalização, bem como do trabalho docente.
\end{abstract}

Palavras-chave: Professor iniciante. Egressos de licenciaturas. Condições de trabalho. Acolhimento profissional.

* Universidade de São Paulo. Faculdade de Educação. E-mail: mialmei@usp.br. https:// orcid.org/0000-0003-2506-2972. E-mail: sgpiment@usp.br. http://orcid.org/0000-0003-0785-890X. E-mail: jfusari@usp.br. https://orcid.org/0000-0002-5779-0811. 


\begin{abstract}
The present article starts by inquiring how the modes of professional insertion of beginning teachers have impacted their professional lives. To find answers to this question, we investigated the ways in which the insertion of new graduates from a public university is carried out when they start their careers as teachers in the public-school systems of the state of São Paulo, Brazil. We interviewed 20 beginning teachers from different areas of knowledge who were working in public schools in the first five years after graduation. The categories of analysis were professional socialization, teacher professionalization and teachers' work. The text seeks to understand how the beginning teachers join the teaching careers, learn from the profession, establish relationships with work partners, approach the professional environment, get inserted in the public system schools, deal with the teaching conditions, get the motivation for joining and staying in the career, and deal with difficulties and expectations regarding the professional future. The qualitative data obtained in the semi-structured interviews were analyzed at the confluence with the literature on the subject and in the light of the critical-dialectic conception, which allowed us to highlight the complexity and contradictions of the processes of socialization and professionalization, as well as of the teachers' work.
\end{abstract}

Keywords: Beginning teacher. New graduate teachers. Teaching conditions. Professional hosting.

\title{
Introdução
}

Nesse artigo discutimos como os modos de inserção profissional de professores iniciantes repercutem na vida desses profissionais, especificamente dos que atuam em escolas dos sistemas públicos de ensino do estado de São Paulo. Para identificar e compreender como se processa a inserção de recém-licenciados na profissão docente e buscando apreender as contradições desse processo, trazemos a análise qualitativa de dados quantitativos, coletados por meio de entrevistas semiestruturadas de pesquisa realizada com egressos de cursos de licenciatura da Universidade de São Paulo ${ }^{1}$. A escolha por esse procedimento metodológico se apoia em Minayo; Sanches (1993), quando sustentam que a pesquisa quanti-

1 Este artigo deriva da pesquisa INSERÇÃO PROFISSIONAL DE LICENCIADOS EGRESSOS DA UNIVERSIDADE DE SÃO PAULO: processos de construção de identidades, socialização profissional e profissionalização docente, financiada pela Fundação de Amparo à Pesquisa do Estado de São Paulo (FAPESP). 
tativa é uma via de acesso aos níveis da realidade, permitindo trazer à luz dados, indicadores e tendências observáveis na população pesquisada. Para as autoras, a pesquisa qualitativa permite abordar valores, crenças, representações, hábitos, atitudes e opiniões, mostrando-se adequada para aprofundar a compreensão de fenômenos, fatos e processos particulares e específicos de determinados grupos.

As 60 entrevistas realizadas com egressos dos 46 cursos de licenciatura da Universidade de São Paulo (USP), foram posteriormente transcritas. Esse material foi analisado numa primeira etapa para se identificar entrevistas que atendiam mais plenamente às questões da pesquisa. Foram priorizadas 20, que se caracterizaram pela extensão e profundidade das reflexões. Optou-se pela interrupção da inclusão de outras entrevistas no momento em que se percebeu que os depoimentos começaram a se tornar reiterativos, deixando de trazer questões novas para os eixos de análise.

Os dados foram analisados à luz da produção teórica sobre as três categorias norteadoras - socialização profissional, profissionalização e trabalho docente-, e por meio das lentes da concepção crítico-dialética, o que permitiu evidenciar a complexidade e as contradições presentes na formação, na construção de saberes e da identidade docente e no trabalho desenvolvido pelos egressos. As entrevistas ocorreram no momento em que a maioria dos egressos tinha entre 5 e 6 anos de experiência profissional, o que nos levou a caracterizá-los como professores iniciantes, fase em que as descobertas da profissão e a busca pela sobrevivência rivalizam-se nos primeiros anos de exercício profissional (HUBERMAN, 1992). O interesse por compreender como se processa a inserção profissional dos professores iniciantes tem crescido internacionalmente e em nosso país. Estudo de Cunha; Braccini; Feldkercher (2015) evidencia essa tendência em balanço da produção apresentada em evento internacional ${ }^{2}$ com foco nessa temática. Dentre os vários ângulos dos estudos acerca do tema, as autoras destacam o crescimento dos que enfocam a situação dos professores iniciantes em contextos desfavoráveis e afirmam: "Certamente esta temática é um sinal dos tempos recentes e indica uma realidade que não pode mais ser ocultada" (CUNHA, BRACCINI; FELDKERCHER, 2015, p. 80). Nacionalmente também tem crescido o interesse por compreender a vida desses professores e pela busca de investimentos pedagógicos, organizacionais e políticos para viabilizar modos mais acolhedores e produtivos de se receber os professores iniciantes nas escolas. Num levantamento parcial sobre estudos realizados sobre o tema nos últimos dez anos, encontramos muitos trabalhos e, dentre eles, os por nós

2 Congreso Internacional sobre Profesorado Principiante e Inserción Profesional a la Docencia. A análise teve como foco as edições realizadas em 2008, 2010 e 2012. 
selecionados por terem articulação mais próxima com nosso foco de estudo serão identificados ao longo do texto.

O início da vida profissional é marcado por descobertas acerca da dinâmica da sala de aula e da escola, por investimentos na sobrevivência profissional. Assim, embora essa fase guarde relações com a história vivida enquanto estudante e, especialmente, com o percurso de formação, é nela que o professor ou a professora iniciante constitui as bases que sustentarão sua atitude docente. Papi; Martins (2010, p. 47), em estudo acerca dos professores, assim se referem a essa fase:

\footnotetext{
"Os primeiros anos de experiência profissional são basilares para a configuração das ações profissionais futuras e para a própria permanência na profissão. Pode tornar-se um período mais fácil ou mais difícil, dependendo das condições encontradas pelos professores no local de trabalho, das relações mais ou menos favoráveis que estabelecem com colegas, bem como da formação que vivenciam e do apoio que recebem nessa etapa de desenvolvimento profissional."
}

Com apoio em Papi; Martins (2010), e de Garcia (1999), podemos considerar que é nessa fase que ocorre um processo de transição do status de estudante para o de professor profissional, marcado por um profundo aprendizado advindo da articulação dialética entre formação profissional e ação pedagógica.

No presente artigo apresentamos os dados oriundos dos entrevistados, analisados a partir de aspectos articulados em torno das três categorias citadas. Para melhor compreendê-las, foram destacados alguns de seus desdobramentos como: formas de ingresso no magistério; o aprender da profissão; relação com os parceiros de trabalho; formas de aproximação com o ambiente profissional; inserção em escolas do sistema público; condições de exercício da docência; dificuldades profissionais; permanência na profissão e expectativas quanto ao futuro profissional.

\section{Sobre a socialização profissional e o aprender da profissão}

Aprender a profissão e empreender esforços de socialização no cotidiano institucional do trabalho docente pressupõe múltiplas relações, compromissos e envolvimentos. Pressupõe o desenvolvimento de uma nova perspectiva, onde os 
recém-chegados à profissão precisarão ter de dar conta de uma seleção intencional de ideias e formas de agir perante as relações complexas e contraditórias com que passarão a conviver cotidianamente, muitas vezes sem ter referências para lidar com elas (SILVA, 1997; PAPI; MARTINS, 2010). Por sua vez, Garcia (1999) considera que é nessa fase que ocorre a intensificação do aprendizado profissional e pessoal. É quando se processam algumas transições importantes: de estudante para professor, de trabalhador leigo para profissional, de sujeito inexperiente para experiente. Constrói-se uma nova identificação, que agora é também profissional.

O processo de socialização envolve distintas fases e a inicial é a mais desafiadora. Nela o sujeito vai se construindo na confluência das suas características e história pessoal e de formação com a realidade do mundo do trabalho docente, que é atravessado por fatores e aspectos profissionais, estruturais, organizacionais e culturais. É o que Dubar (2012, p. 364-5) denomina de "construção de si pela atividade de trabalho", pontuando que "em determinadas condições de organização dos empregos e das formações, o trabalho pode ser formador, fonte de experiências, de novas competências, de aprendizagens para o futuro".

Esses autores anteriormente citados corroboram a importância do trabalho na constituição do professor iniciante e nos ajudam a reafirmar que dependendo do tipo de organização da escola, essas contribuições podem ser mais ou menos formativas, e até mesmo desconstrutoras da profissionalidade em desenvolvimento. É sabido que as culturas institucionais não são neutras. Podem reunir os professores ou separá-los, oferecer oportunidades para a interação e a aprendizagem, ou colocar barreiras que os estimulam a deserção (HARGREAVES, 1999).

Em estudo sobre as vivências de professoras no início da docência, Silveira (2006, p.43) pontua:

o início da aprendizagem profissional da docência é avassalador. A professora é colocada frente a tudo que a escola não está preparada para lidar e o mecanismo sutil parece ser este: a professora é deixada sozinha sem apoio. Assim, ou ela desiste ou, para ser aceita, incorpora o discurso da cultura escolar da exclusão que diz: "não adianta fazer nada", pois sempre foi assim. Aparentemente, a cultura escolar só percebe essas duas possibilidades.

Papi; Martins (2010, p.44) também consideram que os primeiros anos de exercício profissional "são basilares para a configuração das ações profissionais futuras e para a própria permanência na profissão. Podem tornar-se um período mais fácil ou mais difícil, dependendo das condições encontradas pelos professores." Para isso, corroboram as relações com colegas, a formação que 
vivenciam no espaço escolar, os apoios recebidos, as condições para o exercício do trabalho, enfim, as condições do acolhimento profissional.

Por isso, entendemos que para favorecer o início do processo de socialização profissional é necessário sedimentar a vida da escola em bases democráticas, com uma dinâmica de gestão pedagógica participativa, coletiva e comprometida com a aprendizagem e a inclusão de todos no mundo do conhecimento. É importante também pensar mudanças na maneira de formar professores, de ensiná-los a ensinar, para o que se faz imprescindível superar a cultura de isolamento entre as disciplinas e o distanciamento das ações pedagógicas desenvolvidas nas escolas; é essencial ainda uma formação continuada que incentive práticas de diálogo direto com a realidade das escolas e da vida dos professores e gestores.

E considerando a formação como um continuum, é procedente a formulação de Canário (2006) ao defender a escola como local privilegiado de aprendizado profissional por meio da socialização e do desenvolvimento profissional dos professores. Nessa perspectiva, compreendemos que uma formação que não se encerra na universidade e/ou na instituição escolar, deve passar por elas, como um caminho necessário para avançar, para além dos limites que se colocam hoje, sobretudo por parte das políticas neoliberais de formação de professores.

Quando se analisa mais de perto o ambiente escolar, observa-se que o início da inserção profissional sempre envolve um certo choque de realidade decorrente da ruptura que ocorre entre as ideias constituídas na experiência pessoal e na formação inicial, e a dureza da realidade da sala de aula, do contexto escolar e das políticas educacionais (VEENMAN, 1984). Essas experiências, em grande parte desagradáveis, são marcantes e levam a escolhas, a redefinições de caminhos (LIMA, 2006).

Assim, um entrevistado rememora suas primeiras aproximações com a profissão docente:

NKQ - Educação Física A escola foi meu primeiro emprego. No começo eu tive muito choque de realidade por ter estudado sempre em escola particular. Meu primeiro contato com escola pública foi na Faculdade, quando fiz estágio. Encontrei um mundo que não conhecia e foi bem dificil.

Nesse contexto, em grande parte adverso, há os que já não se dispõem a vivenciar a experiência inicial com vistas à reconstituição da própria identidade, que agora passa a ser também uma identidade profissional. É quando o choque de realidade não permite a abertura dos sujeitos para vivenciar um processo de 
socialização, que é complexo e prolongado. Essa professora ajuda a evidenciar esse processo:

MP - História

Dependendo de como as coisas acontecem no inicio, as pessoas decidem se vão ficar ou não. Tenho vários colegas que chegaram numa escola e nunca mais voltaram. Acho que isso acontece porque se chega sem saber da realidade da escola pública.

As experiências vividas no início da carreira vão permitindo aos professores fazer escolhas entre escolas que são mais compatíveis com suas expectativas pessoais e profissionais. E a escola pública mostra-se, muitas vezes, como um espaço de maior liberdade na organização e desenvolvimento do ensino. $\mathrm{O}$ depoimento a seguir explicita essa escolha:

MBAP - Sociologia Tenho total liberdade para organizar meu trabalho. Esse é o grande 'barato' da escola pública - entrou e fechou a sala e ali é você com o que você acredita, com o que pode fazer de melhor com aquele minimo que eles dão. Trago filmes, textos diferentes e aproveito o livro didático.

Os processos de socialização envolvem buscas, construções, ansiedades, escolhas, frustrações, desistências, mas também realizações e adesão à profissão. Souto (2016) encontrou evidencias semelhantes às nossas: aqueles que conseguem superar os momentos mais tensos, angustiantes, desafiadores e contam com uma boa base de formação, conseguem sobreviver no seio da profissão e trafegam de modo mais seguro pela vida profissional, encontrando prazeres em descobrir possibilidades de comprometer-se com a constituição de um modo próprio de professorar.

\section{Sobre a profissionalização docente}

Desde o final do século passado as mudanças que marcam a sociedade contemporânea vêm fazendo com que os problemas escolares deixem de ser 
apenas da área da educação e os problemas sociais, por sua vez, convertam-se em problemas escolares. Vemos então que há um aumento da complexidade do trabalho dos professores, que muitas vezes não estão preparados para dar conta dessa realidade. Por isso eles têm vivido momentos profissionais muito difíceis. Para Fusari (1998, p.177), isso se deve à

existência de políticas que promovem a não democratização de um ensino de qualidade para todos os brasileiros, [o que] foi, ao longo do tem por, desqualificando a carreira do magistério e corroendo a imagem pública dos educadores, principalmente dos que atuam na Educação Básica.

Também Nóvoa (1992, p. 24) apresenta outro aspecto dessa crise que herdamos do século passado quando diz que "esses problemas estão relacionados à tendência de se separar a concepção sobre a prática educacional de sua execução, legitimando a intervenção dos especialistas [...] reforçando as características técnicas do trabalho dos professores".

Quase três décadas depois, Barros e Azevedo (2016) reafirmam a presença das mesmas manifestações ao estudarem o impacto em professores iniciantes de um programa adotado pela rede de escolas públicas do Estado de São Paulo ao afirmarem que "É visível nos dados o sentimento de que foi retirado desses professores a autoria e a autonomia de intervenção profissional".

Tem se tornado cada vez mais evidente que o modo como a profissionalização docente tem se processado leva à degradação do estatuto profissional e à desqualificação do seu trabalho, resultando na queda do seu prestígio social, no decréscimo de sua autoestima e em condições de trabalho e de vida muito deterioradas. Esse quadro é bastante antigo: em pesquisa realizada sobre o perfil dos professores paulistas, Almeida (1991) identificou que apenas $47 \%$ dos seus entrevistados tinham a perspectiva de permanecer na carreira como professor até a aposentadoria e 18\% expressaram a intenção de desistir da profissão, caso encontrassem outras alternativas profissionais. Três anos após, Gatti (1994) constatou, em pesquisa sobre o professorado de $1^{\circ} \mathrm{Grau}^{3}$, que $40 \%$ optaria, se pudesse, por outra profissão. Em 1999, o estudo coordenado por Codo (1999) traçou um extenso panorama analítico da situação vivida pelos professores brasileiros, mostrando o quão afetados estão pelos problemas profissionais e como

3 Em 1971 a Lei de Diretrizes e Bases (LDB) n 5692 fundiu o antigo ensino primário com os 4 anos do ensino ginasial, dando origem ao Ensino de $1^{\circ} \mathrm{Grau}$, com a duração de 8 anos. Em 1996 a LDB n 9394 substituiu o ensino de $1^{\circ}$ grau pelo Ensino Fundamental. 
isso provoca desgaste físico e emocional, levando contingentes significativos ao estado de doença profissional denominado Burnout. Em 2004, em pesquisa realizada junto a professores da educação básica de Goiânia, Guimarães (2004) afirmou que $68 \%$ dos participantes desejavam deixar a docência. No final da $1^{\text {a }}$ década do século XXI, Gatti e Barreto (2009) demonstraram o quanto estamos distantes, enquanto país, de assegurar os padrões mínimos necessários para colocar a profissão docente à altura de sua responsabilidade social. Souto (2016) evidenciou em seu estudo que uma das grandes dificuldades para o exercício da docência relaciona-se com a dinâmica do sistema escolar e as políticas públicas para a educação, especialmente a progressão continuada e a avaliação em larga escala.

Em meio a esse cenário bastante desalentador, é inquestionável o valor social das ações empreendidas pelos professores, o que reforça a necessidade de se analisar a importância desse grupo profissional. Para tanto, há que se considerar o sentido do trabalho humano e, em decorrência, a influência que as profissões exercem sobre a vida das pessoas, como nos lembra Codo (1999, p.135), ao afirmar que "a vida dos homens, sem dúvida, não se reduz ao trabalho, mas também não pode ser compreendida na sua ausência". Nessa direção, acrescenta que "o indivíduo é aquilo que faz".

No processo de tornar-se professor, os que optam por esta profissão vivenciam um verdadeiro choque entre distintas compreensões sobre a docência. Para alguns ela é compreendida como uma profissão que oferece grande potencial de realização, uma vez que os frutos do trabalho podem ser percebidos por seus realizadores e por aqueles que acompanham o processo educativo de seus filhos. Também, por ser um trabalho que permite o exercício da criatividade, estimula e cobra o crescimento pessoal e profissional, possibilita o controle sobre o próprio trabalho e o exercício da responsabilidade sobre os resultados alcançados. Acima de tudo, possibilita o prazer de saber-se importante para o outro. Porém, para viver a docência desse modo, é preciso estabelecer uma relação profissional em que o sujeito professor esteja envolvido com o seu fazer em toda a sua plenitude. $\mathrm{O}$ depoimento a seguir evidencia a satisfação com a atividade profissional e o quanto ela depende da ação positiva da escola e dos colegas:

ABN - História Nossa coordenadora foi quem começou a atualizar o projeto pedagógico. A gente partiu do estudo do meio, e cada sala ficou responsável por trabalhar um aspecto do bairro. E nós, professores, fomos ao morro onde vivem os alunos. Conhecer essa realidade me ajudou a entender as dificuldades que eles tinham... 
Mas, há também uma outra compreensão sobre a docência, onde o fazer docente é compreendido como um fazer técnico, baseado na aplicação de formulações elaboradas externamente ao próprio trabalho e ao local onde ele ocorre (BARROS; AZEVEDO, 2016). Nessa percepção, a construção coletiva do projeto de trabalho inexiste, a criatividade é atrofiada e a co-responsabilização dos envolvidos no processo dá lugar à culpabilização do seu elo mais frágil - o professor. Esse fenômeno da culpabilização vem gerando novos estudos a respeito da situação dos docentes, como o de Cavalcanti; Nascimento; Ostermann (2018). Mesmo que se leve em conta a possibilidade de realização inerente, a profissão docente situa-se na contradição do discurso entre a valorização do magistério e as políticas educacionais que normatizam inovações sem levar em conta as relações de trabalho dos professores.

A despeito de todo esse cenário, o processo de adentrar na profissão é sobrecarregado por aprendizagens práticas sobre o desenvolvimento efetivo da ação pedagógica. Após ter estudado para ser um profissional do ensino, o professor iniciante tem que operar um entrecruzamento de fios que lhe darão amparo na tomada de decisões de distintas naturezas, que agora serão de sua responsabilidade. As primeiras aproximações com o contexto escolar são vitais nesse momento. Compreender onde pisará, ou seja, a natureza organizativa da escola, seu funcionamento prático, bem como o lugar e o poder de cada segmento que a compõe são essenciais para que o recém-chegado se sinta minimamente amparado para aí iniciar sua experiência profissional. O depoimento a seguir evidencia a importância desse acolhimento:

$\mathrm{ABN}$ - História A coordenadora foi a primeira pessoa que me acolheu. Ela me mostrou toda a escola, foi muito paciente em explicar tudo, em ter essa sensibilidade de perceber que eu era nova, e teve esse cuidado de me manter informada.

Porém, a maior parte dos entrevistados evidenciou o oposto - a forma predominante de recepção do recém-chegado é negativa:

ERT - Biologia Eu fui acolhida com indiferença, é uma a mais... fui sozinha conhecer a escola e apenas conversei superficialmente com a diretora e a coordenadora. Como entra e sai muito professor, não tem acolhimento. 
Na medida em que o processo de profissionalização avança, o professor desenvolve compreensões acerca do seu trabalho, da própria escola e da profissão. Nas palavras de Romanowski; Martins (2013, p. 4), ele faz descobrimentos "sobre a prática e seus problemas, e sobre as alternativas possíveis para resolvê-los". Como fruto da combinação dos conhecimentos teóricos, das experiências pessoais, da convivência com colegas, autoridades escolares e alunos, ele vai formulando visão crítica e proposições a respeito do que pode e necessita mudar na escola. Como em qualquer espaço público, mudanças pontuais e até mesmo transformações profundas precisam ser construídas e buriladas coletivamente.

As análises até aqui realizadas, acerca das vivências e compreensões dos professores sobre a profissão docente, mostram o quão é forçoso reconhecer que dentre eles predomina a visão de que a profissão vive um período de profunda desvalorização que se expressa na baixa remuneração salarial, na desvalorização do trabalho empreendido, na deterioração das condições de trabalho, na gestão escolar autoritária, dentre outros. Essa visão expressa pelos entrevistados faz coro com a literatura até aqui mobilizada, que há mais de quatro décadas vem evidenciando o descaso das políticas educacionais em todos os níveis. Esse cenário é também evidenciado por Sampaio; Stobaus; Baez (2017), que reafirmam as vivências do mal-estar docente - entendido como dificuldade ao lidar com a realidade da sala de aula povoada por alunos concretos -, o clima relacional instável entre docentes e a falta de apoio pedagógico e psicológico por parte da escola.

\section{Sobre o trabalho docente}

O consenso a respeito da importância dos professores no processo educativo tem contribuído para o crescimento do interesse por compreender a profissão docente, para além do que se conhece do seu exterior. Isso se evidencia pelo volume de livros e artigos publicados sobre os professores, sua formação e sua profissão, pela quantidade de pesquisas que têm buscado analisar os contextos que permeiam a atuação docente e pelo alto grau de participação em congressos, encontros, jornadas ou debates, que discutem os problemas da profissão.

Porém, são inúmeras as evidências de que em meio a esse consenso a categoria docente vive uma fragilização de seu status profissional, em parte decorrente de transformações sociais ocorridas especialmente a partir da metade do século passado, quando se destacam as alterações do próprio conhecimento, da cultura e dos valores sociais, que priorizam o sucesso e a recompensa financeira 
individual como sinônimos de status e de reconhecimento social em detrimento dos valores humanistas. Com isso, profissões que estão sendo mal remuneradas como a de professor, passam a ser socialmente desvalorizadas e contam com poucos interessados em abraçá-las como opção de carreira. Outras alterações importantes se passam no âmbito da evolução científica e tecnológica, acelerando o ritmo de produção do conhecimento e abreviando sua validade, e também no âmbito da facilidade e rapidez com que o acesso à informação ocorre para parcelas cada vez maiores da população, colocando em xeque o tradicional papel da escola. Os baixos salários acentuam o desinteresse dos jovens pela profissão docente, pois são fortes sinalizadores da necessária jornada diária estafante e da carga de trabalho adicional à própria jornada. E como amálgama de todas essas dificuldades, há o papel das políticas educacionais, que há décadas vêm solapando o prestígio da profissão e as condições de seu exercício.

Segundo pesquisa realizada pela Varkey Foundation em 2018 (DONTON et al., 2018), dentre 35 países pesquisados o Brasil é o que menos valoriza seus professores, ficando atrás de outros do continente sul-americano como Argentina $\left(31^{\circ}\right)$, Colômbia $\left(26^{\circ}\right)$, Peru $\left(25^{\circ}\right)$, Chile $\left(22^{\circ}\right)$ e Panamá $\left(15^{\circ}\right)$.

É reconhecido que a atratividade das profissões aparece frequentemente ligada à questão dos salários que ofertam aos seus integrantes. E historicamente, as condições salariais dos professores nunca foram consideradas justas frente ao tempo de estudo e preparo requeridos, se comparadas com as de outras profissões com os mesmos requisitos formativos. Os salários dos professores não são recompensadores, dificultando o ingresso e a permanência de profissionais capacitados na docência. Segundo Gatti (1994), os salários aviltantes aparecem como um fator perturbador que causa a desarticulação dos sistemas públicos de ensino. Behrsin (2011), assim como outros pesquisadores, encontra a mesma manifestação ao ouvir ou sujeitos de sua pesquisa. É exatamente dessa insatisfação que trata o relato a seguir por nós encontrado:

MP - História Estou numa escola que funciona muito bem. Mas o salário é muito ruime isso está me fazendo começar a pensar que no ano que vem vou procurar outras escolas, talvez particular porque paga mais, não é?

Mas as insatisfações vividas pelos professores não se restringem ao campo salarial e à carreira. Há muitas dificuldades decorrentes do choque entre o que é estabelecido pelas políticas educacionais, traduzidas em lei e normas que se desdobram nas orientações para o funcionamento da escola, e a realidade 
cotidiana vivenciada no exercício da docência. As manifestações a respeito dessas contradições envolvem o próprio projeto político pedagógico, que é uma quimera em muitas delas; os modos como se dá a participação, e se desenvolvem as discussões nos horários pedagógicos coletivos, existindo até mesmo a exclusão daqueles que não têm jornada de 25 horas; a presença de professores sem formação e preparo no exercício da coordenação pedagógica das escolas estaduais; a pouca efetividade da inclusão, uma vez que tanto as escolas como os professores não têm preparo para trabalhar com crianças e jovens portadores de necessidades especiais, dentre outros tantos aspectos. Vejamos como se manifesta um dos entrevistados sobre uma dessas contradições:

MCS - Geografia O projeto pedagógico de todas as escolas que trabalhei parece ficar num cofre forte - ele é praticamente inacessivel aos professores. Fala-se dele, dizem que é discutido, mas na realidade apenas se define as metas que a diretoria regional quer, mas o plano político pedagógico real não é discutido.

A precariedade das relações dos professores com as instituições em que trabalham - e que são vinculadas à rede estadual ou às redes municipais - é fonte de insegurança profissional. Uma das vias que alimentam essa insegurança é a grande distância temporal na realização de concursos para ocupação dos cargos no magistério público, fenômeno que ocorre com maior incidência na rede estadual de ensino. Quando realizados, têm ainda baixos índices de aprovação. O resultado é que isso leva à existência de muitos professores contratados temporariamente para suprir a falta de efetivos. Os baixos índices de aprovação apontam deficiências na formação dos professores, mas também podem revelar a arbitrariedade das provas aplicadas aos candidatos a professor, como perguntas incoerentes, formulação da prova por diferentes instituições etc.

A pesquisa de Brito (2013) aponta para a presença de contratos temporários como expressão da desvalorização da profissão. A instabilidade profissional gerada pela longa distância entre os concursos e o aumento das contratações temporárias levam à mobilidade de docentes de forma a prejudicar seu envolvimento e comprometimento com projetos, individuais ou coletivos, com a escola e com os alunos. Os professores temporários têm dificuldades de criar vínculo se constituir equipes com outros professores também pelo fato de lecionarem um número pequeno de aulas em diversas escolas, como recurso para complementar a baixa remuneração. Portanto, além da insegurança causada pelos salários 
insuficientes, os professores temporários sofrem com a falta de estabilidade no emprego. Inexiste, além de motivação e condições para o planejamento de aulas, um projeto de ensino contínuo com os alunos e de cooperação com os colegas de profissão. Assim se manifesta um entrevistado sobre esse tema:

CJAR - Filosofia A precarização dos professores que entram sem concurso é danosa. Nessa condição de trabalho ele não se compromete porque não sabe se tem futuro. Então cai a qualidade, cai o interesse, porque professor que não tem perspectiva de continuar na carreira não vai se preocupar em se aprimorar.

É recente a pressão sobre os docentes no sentido de que assumam cada vez mais tarefas e responsabilidades, exigindo que o tempo de trabalho seja intensificado e compartimentado, como já apontava Michel Apple em 1990. Para o autor, esse processo acarreta ainda a corrosão da autonomia dos professores, que não têm mais tempo para atividades de sua livre iniciativa, uma vez que a vida profissional está totalmente pautada pelas políticas em vigor.

Visto por outro ângulo, nesse processo os professores perdem o controle do próprio tempo, dimensão estruturante do seu trabalho. Daí parece-nos ser novamente pertinente sinalizar o crescente esvaziamento da formação e atuação dos professores, cada vez mais destituídos das condições para estabelecer os objetivos e os rumos do seu trabalho. Enguita (1990) já apontava há cerca de três décadas que com essa perda, os professores são facilmente "colonizados", adotando o que é pensado e proposto externamente ao seu trabalho. Entre nós, esse processo de colonização ganha feições perversas com a imposição das chamadas "apostilas" nas escolas estaduais e os "cadernos" nas escolas municipais da capital, dentre inúmeras ações verticalizadas.

Também têm forte impacto na organização do trabalho docente as formas como as avaliações externas vêm sendo usadas pelos sistemas de ensino. Além de se prestarem ao controle do que é pedagogicamente desenvolvido em sala de aula, cumprem, em algumas redes, o papel de atrelar o salário dos docentes aos resultados dos alunos nessas avaliações. Prestam-se para culpabilizar os professores pelos resultados negativos dos estudantes, como se fosse possível relacionar os resultados das provas apenas à ação docente, isolando-a de todos os demais fatores intervenientes na formação escolar, como apontam Machado; Alavarse (2014), Chirinea; Brandão (2015), Werle (2011), Bauer; Alavarse; Oliveira (2015). Assim, por força de interesses diversos, externos ao processo 
educativo, os professores passaram a ser apontados como principais responsáveis pelas deficiências do ensino.

Esses fatores negativos interferem no trabalho docente acentuando a desprofissionalização do magistério, movimento silencioso e constante que aprofunda a perda das possibilidades de desenvolvimento profissional, de aprimoramento do trabalho educativo. $\mathrm{O}$ depoimento a seguir é contundente na confirmação dessa compreensão:

ERT - Biologia Quando prestei concurso e entrei na Prefeitura, comecei a trabalhar como professora de Ciências, só que eu não conseguia dar aula sem preparar. Tínhamos direito a 10 dias de abono, então eu faltava e usava esses dias para preparar aula.

O crescimento e a complexidade das demandas, articulados à deterioração das condições para o exercício da docência, evidenciam um outro problema - o da evasão de professores. Em estudo realizado em 2011, Gatti; Barreto; André (2011) denunciam uma verdadeira "evasão dos professores melhor capacitados", o que, segundo as autoras, coloca a questão de como reter nas escolas públicas os bons professores. Essa migração para outras carreiras ou para a rede privada de ensino influencia, simultaneamente, a situação educacional brasileira atual e o status simbólico da profissão docente, processos que se relacionam dialeticamente.

O quadro de sobrecarga, tensões, poucas retribuições pelo trabalho e muitas frustrações, acaba por incidir sobre a disposição para continuar no magistério. E é sobre a "desistência da profissão" que trata o relato a seguir:

$\mathrm{ADF}$ - Letras No meu círculo social eu sou a única que continuo na docência após concluir os estudos. Eu tenho 5 amigas que estudaram comigo, mas elas simplesmente desistiram...

O estado de insatisfação vivido pelos professores é decorrente de contradições nos planos econômico, institucional, pedagógico, relacional e social, que se interligam com preponderância de um ou mais fatores em momentos específicos da trajetória. 
Em que pesem esses fatores negativos, quando da realização das entrevistas perguntamos aos jovens professores sobre seus projetos futuros e o que ouvimos fala do desejo de continuar professor, porém em condições mais favoráveis. A continuidade dos estudos, a necessidade de ter melhores condições para efetivação do trabalho e de toda a carga extraclasse que lhe é peculiar, a importância de ter mais condição financeira para dar conta das múltiplas necessidades da vida pessoal-familiar e de não precisar correr de uma escola para outra, são aspectos que deveriam constituir parte dos direitos de quem se dedica a uma profissão que é tão importante socialmente. No entanto, essas condições foram colocadas pelos entrevistados como parte de sonhos difíceis de serem alcançados. E, efetivamente, a realidade nos mostra que poucos conseguem realizá-los.

FSL - Letras Eu gostaria de continuar lecionando. Gostaria que isso fosse com menos desgaste, até porque é muito desgastante trabalhar 12 horas por dia. Eu tenho vontade de fazer um mestrado. Mas com os horários que tenho hoje, é impossivel.

A grande questão que permeia essas manifestações dos professores iniciantes é a dificuldade de conciliar as exigências da profissão e o desgaste dela resultante, com projeto de vida, sonhos e desejos, de modo a assegurar espaço e condições para o desenvolvimento pessoal. Todos manifestam um compromisso educativo que se coloca como norteador de suas ações e decisões, mas também enfatizam as dificuldades para caminhar na direção dos sonhos e dos desejos.

O futuro profissional é incerto no magistério atualmente. Muitas vezes, mesmo aqueles que pretendem permanecer na carreira docente, ao não encontrarem oportunidade considerada adequada ou condições profissionais favoráveis, tendem a migrar para outra área profissional.

\section{Considerações finais}

A análise realizada a partir dos dados da pesquisa sobre a inserção profissional dos egressos da Universidade de São Paulo em diálogo com a literatura da área, nos permite apontar para o grande fosso existente entre a finalização de um curso de licenciatura e o ingresso no magistério em escolas públicas. 
A profissão de professor tem sido vitimada pela crescente perda de status social, fenômeno que tem nos baixos salários sua maior expressão; esse é o principal fator apontado pelos professores egressos como responsável pela falta de identificação com a profissão.

A situação da educação e o valor social atribuído à docência são dois fatores que interagem dialeticamente, compondo e forjando as experiências e as identidades dos professores egressos, seja como indivíduos, seja como classe, confirmando, assim, a afirmação de Pimenta (1999) de que uma identidade profissional se constrói a partir da significação social da profissão e dos significados sociais a ela atribuídos pelas instituições sociais e políticas, pelos sistemas de ensino, pelas culturas geracionais, pelos pais, alunos e pelos próprios professores. O que se pode perceber nos depoimentos dos egressos é que os sistemas públicos operam no sentido da desconstrução das identidades dos seus docentes.

Frente a esse quadro há que se constatar que a qualidade educacional brasileira ainda está distante do que se pode chamar de razoável nas redes públicas (e privadas) de ensino. A difícil situação profissional evidenciada nos depoimentos dos egressos denuncia que, nas políticas neoliberais, os professores são responsabilizados pelas falhas e dificuldades presentes na aprendizagem. Essas políticas não consideram as precariedades existentes nas escolas e nos sistemas para a qualidade do trabalho realizado nem para a necessária socialização e desenvolvimento profissional dos professores e sua permanência na carreira.

Além da falta de recursos no ambiente escolar que acarretam a precarização das condições de trabalho, os professores sofrem com a má remuneração, o que leva muitos a terem que complementar sua renda. A combinação desses elementos tem impacto direto na baixa autoestima do professor, o que prejudica sua relação com os alunos e a comunidade escolar.

Este estudo, em sintonia com outros com o mesmo foco, constata que, em oposição à difícil realidade vivida pelos professores, é possível supor que quando eles são bem remunerados e possuem elevada autoestima, tendem a ser mais dedicados, dispostos a enfrentar os desafios que encontram e interessados na construção do conhecimento por seus alunos, contribuindo, assim, para que se cumpra a finalidade social da escola pública, gratuita e laica.

\section{REFERÊNCIAS}

ALMEIDA, M. I. O perfil dos professores do ensino público paulista. 1991. São Paulo: FEUSP. Dissertação de mestrado. 1991. 
APPLE, M. Trabajo, enseñanza y discriminación sexual. In: POPKEWITZ, T. (Org.). Formación Del profesorado - tradición, teoria y práctica. Valência: Univ. de Valência, 1990. p. 55-78.

BARROS, R. A.; AZEVEDO, M. A. R. O impacto do 'programa São Paulo faz escola' em professores iniciantes. Educação \& Realidade, Porto Alegre, vol. 41, n. 2, p.359$381,2016$.

BAUER, A.; ALAVARSE, O. M. e OLIVEIRA, R. P. Avaliações em larga escala: uma sistematização do debate. Educ.\& Pesq. São Paulo, vol. 41, n. especial, p. 1367-82, 2015.

BEHRSIN, M. C. D. Vozes docentes: análise de reflexões de professores de ciências sobre sua vivência profissional. Revista Ensaio, 13, 1, 73-86, 2011.

BRITO, V. L. A. O plano nacional de educação e o ingresso dos profissionais do magistério da educ. básica. Educação \& Sociedade, Campinas, vol. 34, n. 125, p. 1251-1267, 2013.

CANÁRIO, R. A escola tem futuro? Das promessas às incertezas. Porto Alegre: Artmed, 2006.

CAVAlCANTI, C. J. H.; NASCIMENTO, M. M.; OSTERMANN, F. A falácia da culpabilização do professor pelo fracasso escolar. Revista Thema, Pelotas, v. 15, n. 3, p. 1064-1088, 2018. Disponível em: https://lume.ufrgs.br/handle/10183/188331. Acesso em: mar. 2019.

CHIRINEA, A. M.; BRANDÃO, C. F. O IDEB como política de regulação do Estado e legitimação da qualidade: em busca de significados. Ensaio: Aval. Pol. Públ. Educ., Rio de Janeiro, vol. 23, n. 87, p. 461-484, 2015. Disponível em: http:/www.scielo.br/pdf/ ensaio/v23n87/0104-4036-ensaio-23-87-461.pdf. Acesso em: mar. 2019.

CODO, W. (Coord.). Educação: carinho e trabalho. Petrópolis: Vozes, 1999.

CUNHA, M. I.; BRACCINI, M. L.; FELDKERCHER, N. Inserção profissional, políticas e práticas sobre a iniciação à docência: avaliando a produção dos congressos internacionais sobre professorado principiante. Avaliação: Revista da Avaliação da Educação Superior, Campinas, v. 20, n. 1, p. 73-86, 2015. Disponível em: http://periodicos.uniso. br/ojs/index.php/avaliacao/article/view/2166. Acesso em: mar. 2019.

DOLTON, R.; MARCENARO, O.; VRIES, R.; SHE, P. Global Teacher status Index 2018. Londres: Varkey Foundation. 2018. Disponível em: https://www.varkeyfoundation. org/media/4790/gts-index-9-11-2018.pdf. Acesso em: fev. 2019.

DUBAR, C. A construção de si pela atividade de trabalho: a socialização profissional. $C a$ dernos de Pesquisa, São Paulo, v. 42 n. 146, p. 351-367, 2012. Disponível em: http://www. scielo.br/scielo.php?pid=S0100-15742012000200003\&script=sci_abstract\&tlng=pt. Acesso em: mar. 2019.

ENGUITA, M. F. Educar en tempos incertos. Madrid: Morata, 1990. 
FUSARI, J. C. Formação contínua de educadores - um estudo de representações de coordenadores pedagógicos da Secretaria Municipal de Educação de São Paulo.Tese de doutorado. Faculdade de Educação-USP. 1998.

GARCIA, C. M. Formação de professores: para uma mudança educativa. Porto: Porto Editora, 1999.

GATTI, B. Formação de Professores e carreira. Campinas: Autores Associados. 1994. CO, 2009.

\& BARRETO, E. Professores do Brasil: impasses e desafios. Brasília: UNES\& ANDRÉ, M. D. A. Políticas Docentes no Brasil: um estado da arte. Brasília, UNESCO, 2011.

GUIMARÃES, V. S. Formação de professores: saberes, identidade e profissão. Campinas: Papirus, 2004

HARGREAVES, A. Profesorado, cultura y post modernidad. Madrid: Morata. 1999.

HUBERMAN, M. O ciclo de vida profissional dos professores. In: NÓVOA, A. (Org.). Vidas de professores. Porto: Porto Editora, 1992. p. 31-62

LIMA, E. F. Sobrevivências: no início da docência. Brasília: Líber Livro, 2006.

MACHADO, C. \& ALAVARSE, O. M. Qualidade das escolas: tensões e potencialidades das avaliações externas. Educação \& Realidade. vol. 39, n. 2, p. 413-436, 2014. Disponível em: http://www.scielo.br/scielo.php?pid=S2175-62362014000200005\&script=sci abstract\&tlng=pt. Acesso em: mar. 2019.

MINAYO, M. C. S.; SANCHES, O. Quantitativo-qualitativo: oposição ou complementaridade? Cad. Saúde Pública, Rio de Janeiro, vol. 9, n. 3, 1993.

NÓVOA, A. (Org.). Os professores e sua formação. Lisboa: Ed. Dom Quixote. 1992.

PAPI, S. O. G.; MARTINS, P. L. O. As pesquisas sobre professores iniciantes: algumas aproximações. Educação em Revista, Belo Horizonte, vol. 26, n. 3, p. 39-56, 2010

PIMENTA, S. G. Formação de Professores: saberes e identidade. In: PIMENTA, S. G. (Org.). Saberes pedagógicos e atividade docente. São Paulo: Cortez, 1999.

ROMANOWSKI, J. P. \& MARTINS, P. L. O. Desafios da formação de professores iniciantes. Páginas de Educación, Montevideo, vol. 6, n. 1, 2013. Disponível em: http:// www.scielo.edu.uy/scielo.php?script=sci_arttext\&pid=S1688-74682013000100005\&ln $\mathrm{g}=\mathrm{es} \& n r m=$ iso\&tlng=pt. Acesso em: fev. 2019.

SAMPAIO, A.; STOBAUS, C. D.; BAEZ, M. A. Vivências de mal-estar na transição da licenciatura à docência. Movimento, Porto Alegre, v. 23, n. 3, p. 975-988. 2017. Disponível em: https://seer.ufrgs.br/Movimento/article/view/65257. Acesso em: fev. 2019.

SILVA, M. C. Primeiro ano de docência: o choque com a realidade. In: ESTRELA, M. T. (Org.). Viver e construir a profissão docente. Porto: Porto Editora, 1997. p. 51-80. 
SILVEIRA, M. F. L. O início da docência - compromisso e afeto, saberes e aprendizagens. In: LIMA, E. F. (Org.). Sobrevivências: no início da docência. Brasília: Líber Livro, 2006. p. 39-54.

SOUTO, R. M. A. Egressos da licenciatura em matemática abandonam o magistério: reflexões sobre profissão e condição docente. Educação e Pesquisa, São Paulo, v. 42, n. 4, p. 1077-1092, 2016. Disponível em: http://www.scielo.br/scielo.php?pid=S1517-97022016000401077\&script=sci_abstract\&tlng=pt. Acesso em: mar. 2019.

VEENMAN, S. Perceived Problems of beginning teachers. Review of Educational Research.v. 54, n. 2, p. 143-178, Summer, 1984. Disponível em: http://citeseerx.ist.psu.edu/ viewdoc/download?doi=10.1.1.834.9292\&rep=rep1\&type=pdf. Acesso em: fev. 2019.

WERLE, F. O. C. Políticas de avaliação em larga escala na educação básica: do controle de resultados à intervenção nos processos de operacionalização do ensino. Ensaio: Aval. Pol. Públ. Educ., Rio de Janeiro, vol. 19, n. 73, p. 769-792, 2011.

Texto recebido em 19/04/2019.

Texto aprovado em 02/10/2019. 